\title{
Droplet departure modeling and a heat transfer correlation for dropwise flow condensation in hydrophobic mini-channels
}

\author{
Xi Chen ${ }^{\mathrm{a}, \mathrm{b}}$ and Melanie M. Derby ${ }^{\mathrm{a} *}$ \\ ${ }^{a}$ Kansas State University, Manhattan, KS, USA \\ ${ }^{\mathrm{b}}$ Intel Corp., Hillsboro, OR, USA \\ *Corresponding Author: derbym@ksu.edu, 3002 Rathbone Hall, Manhattan, KS 66506
}

\begin{abstract}
Droplet nucleation, growth, coalescence, and departure control dropwise condensation heat transfer. Smaller droplets are associated with higher heat transfer coefficients due to their lower liquid thermal resistances. Unlike quiescent dropwise condensation with gravity-driven droplet departure, droplet departure sizes in flow condensation are governed by flow-droplet shear forces and droplet-solid adhesive forces. This research models droplet departure, droplet size distributions, and heat transfer through single droplets under different flow conditions. Heat transfer through single droplets includes the thermal resistances at the vapor-liquid interface, temperature depression across the curved surface, conduction in the liquid droplet, and conduction through the surface promoter (e.g., Teflon). Droplet size distributions were determined for two ranges using the population balance method and power law function for small and large droplets, respectively. Droplet departure sizes (e.g., 10-500 $\mu \mathrm{m}$ ) were derived using force balances between drag forces (obtained using FLUENT) and droplet-solid adhesive forces (determined using a third-order polynomial for contact angle distribution along contact line). The analytical model was compared to experimental flow condensation heat transfer data in a Teflon $\mathrm{AF}^{\mathrm{TM}}$-coated rectangular mini-gap with hydraulic diameters of 0.95 and $1.8 \mathrm{~mm}$. The correlation was compared against experiments with a steam mass flux range of $35-75 \mathrm{~kg} / \mathrm{m}^{2} \mathrm{~s}$ and quality of $0.2-0.9$. There was good agreement between the model and experimental data; without any
\end{abstract}


curving fitting, the mean absolute errors of the heat transfer correlation were $9.6 \%$ and $8.8 \%$ respectively for the $0.95-\mathrm{mm}$ and $1.8-\mathrm{mm}$ mini-gaps.

KEY WORDS: Mini-channel, dropwise condensation, droplet dynamics, hydrophobicity, wettability, correlation

\section{HIGHLIGHTS}

- Single droplet heat transfer was integrated over droplet sizes up to departure.

- Droplet departure sizes obtained through the balance of drag and adhesion forces.

- A heat transfer coefficient model was developed for dropwise flow condensation.

- Correlation compared to experimental flow condensation in 0.95 and $1.8 \mathrm{~mm}$ channels.

- With no curve fitting, model agrees with the experimental results well (MAE $<10 \%)$.

\section{INTRODUCTION AND LITERATURE REVIEW}

Due to large latent heat of water, steam condensation is an important process in industries such as thermal power plants [1, 2], desalination [3], fuel cells [4], air conditioning systems [5], water harvesting [6], and electronic device cooling [7]. An improved fundamental understanding of steamside condensation can improve heat transfer performance and reduce the size of condensers [8]. Changing condensation modes from filmwise condensation, typically observed on hydrophilic, metallic surfaces, to dropwise condensation on hydrophobic or superhydrophobic surfaces can greatly increase heat transfer. Schmidt et al. [9] first recognized 5-7 times higher heat transfer coefficients in dropwise condensation rather than filmwise condensation.

Subsequent research investigated many parameters impacting dropwise condensation, including nucleation mechanisms [10], nucleation density [11-13], subcooling degree [14], droplet size [1416], surface structures $[17,18]$, channel geometry [19], steam velocity [8, 20], heat flux [20], and saturation pressure [16, 21]. Lee et al. [13] numerically studied dropwise condensation on a nanopin-structured surface on which nucleation density was tunable by changing nano-pin dimensions and spacing. Higher condensation heat fluxes were achieved as nucleation sites increased. Tanasawa and 
Ochiai [15] obtained time-averaged steady-state dropwise condensation by wiping the surface periodically. Various sweeping periods generated different maximum droplet sizes, where higher time-averaged heat transfer coefficients were associated with smaller maximum droplet sizes and higher wiping rates. Immediately after the surface was cleared, extremely high transient heat transfer coefficients (greater than $1 \mathrm{MW} / \mathrm{m}^{2} \mathrm{k}$ ) were measured. Hatamiya and Hiroaki [21] experimentally studied dropwise condensation of steam on a variety of surfaces (e.g., gold-plated copper, ultrafinished gold disk, gold-vapor deposited silicon disk, and chromium plated copper) at different saturation pressures. Under the same conditions, smaller droplets seemed to be more densely populated on the gold-plated surface and provided higher heat transfer coefficients. With similar droplets sizes, similar heat transfer coefficients were observed on two surfaces.

In dropwise condensation, a periodic motion of droplet nucleation, coalescence, and departure can be driven by gravitational or shear forces. This cyclical process promotes nucleation and reduces the liquid film thermal resistance, which provides order-of-magnitude-higher heat transfer coefficients than filmwise condensation. Heat transfer coefficients were found to decrease with increasing droplet contact angle hysteresis, which generally corresponds to higher contact angle and easier droplet rolling [22]. Ma et al. [23] proposed that dropwise condensation heat transfer coefficients were related to the surface free energy difference between the condensate and the solid surface. Lower surface energies, associated with higher contact angles, promoted dropwise condensation. Surface modifications such as organic polymer coatings [24-30], self-assembled monolayers (SAM) [13, 3136], ion implantation [37-40], electroplating [41], mini/micro/nano-structures [17, 42, 43] and biphilic patterns [8, 14, 18, 44, 45] decreased surface energy and eased droplet roll-off, thereby promoting dropwise condensation and increasing heat transfer coefficients compared to filmwise condensation. 
In dropwise condensation, saturated vapor deposits on condensation surfaces and forms small droplets, which grow until external forces (i.e. gravity or shear forces) sweep them away. Few studies have created correlations to predict dropwise condensation. Le Fevre and Rose [46] analyzed condensation heat transfer through single droplets using an electrical resistor analogy. The results agreed with gravity-driven dropwise condensation on vertical films at heat fluxes of $0.3-1.8 \mathrm{MW} / \mathrm{m}^{2}$. They also proposed the idea of determining heat transfer rates through single droplets, and then integrating over the range of droplet sizes to obtain the average heat transfer rate on condensation surfaces. They visualized dropwise condensation and correlated a power-law function for droplet size distribution with heat transfer coefficient obtained in their previous work [47], through which they developed the first dropwise condensation heat transfer coefficient correlation with four experimentally determined coefficients. Graham and Griffith [48] derived the minimum stable droplet size through mechanics and thermodynamics analysis, and Tanaka [49] observed that the power-law function works well for droplets growing through coalescence but not for smaller droplets growing through direct condensation. Population theory [11, 22, 49-51] considers conservation of droplet numbers in certain ranges of droplet sizes as well as sweeping effects.

Due to the importance of modeling and predicting dropwise condensation, the objectives of this paper are to develop a model for internal flow dropwise condensation where shear forces drive droplet incipient motion.

\section{CORRELATION DEVELOPMENT}

\subsection{Overall heat transfer coefficient modeling approach}

Depending on flow conditions (e.g., mass flux and quality), rivulets and liquid streams can form on hydrophobic surfaces concurrent with dropwise condensation [52], as shown in Fig. 1. Filmwise condensation models are used to describe rivulets and streams in section 2.2. Dropwise heat transfer 
coefficients are estimated by integrating single droplet heat transfer for the range of droplet sizes encountered, as described in sections 2.3-2.6, and the dropwise flow condensation correlation is compared to experimental data in section 3.

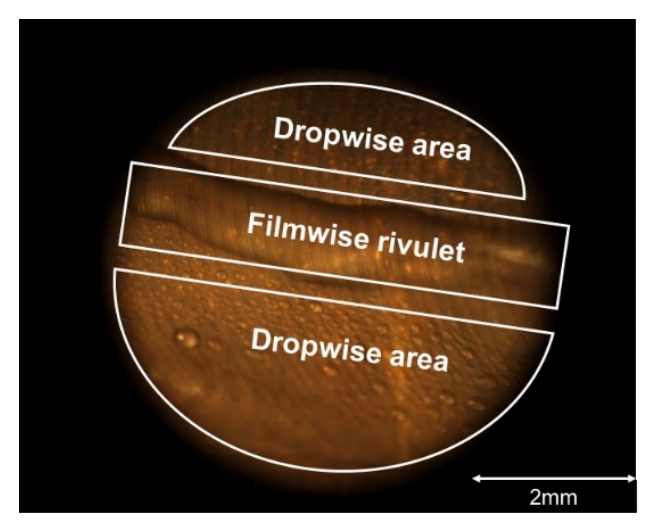

Fig. 1 Filmwise condensation region and dropwise condensation region during steam

\section{condensation on hydrophobic surfaces}

Average flow condensation heat transfer coefficients on hydrophobic surfaces $(\bar{h})$ are weighted by the fractional areas undergoing filmwise and dropwise condensation,

$$
\bar{h}=\frac{A_{F W} h_{F W}+A_{D W} h_{D W}}{A_{t}}=\frac{A_{F W}}{A_{t}} h_{F W}+\frac{A_{D W}}{A_{t}} h_{D W}
$$

where $A_{F W}, A_{D W}$, and $A_{t}$ are filmwise, dropwise, and total areas, respectively, and $h_{F W}$ and $h_{D W}$ are filmwise and dropwise heat transfer coefficients, respectively. The filmwise and dropwise condensation areas are estimated using void fraction,

$$
\frac{A_{F W}}{A_{t}} \cong 1-\alpha ; \frac{A_{D W}}{A_{t}} \cong \alpha
$$

where void fraction, $\alpha$, is obtained using the Lockhart-Martinelli correlation [53] assuming turbulent liquid and turbulent vapor,

$$
\frac{1-\alpha}{\alpha}=0.28\left(\frac{1-x}{x}\right)^{0.64}\left(\frac{\rho_{v}}{\rho_{l}}\right)^{0.36}\left(\frac{\mu_{l}}{\mu_{v}}\right)^{0.07}
$$

where $x$ is quality, $\rho$ is density, and $\mu$ is dynamic viscosity. 


\subsection{Filmwise condensation modeling}

The filmwise condensation heat transfer coefficient is obtained from the Kim and Mudawar [54] mini-channel flow condensation correlation for annular flows [e.g., $W e^{*}>7 X_{t t}^{0.2}$, Equation (4)] and slug-bubbly flows [e.g., $W e^{*}<7 X_{t t}^{0.2}$, Equation (5)]. $W e^{*}$ is the modified Weber number as defined by Soliman [55] and $X_{t t}$ is turbulent-turbulent Lockhart-Martinelli parameter,

$$
\begin{gathered}
h_{F W}=\frac{k_{l}}{D_{h}}\left[\left(0.048 R e_{l}^{0.69} \operatorname{Pr}_{l}^{0.34} \frac{\Phi_{v}}{X_{t t}}\right)^{2}\right]^{0.5} \\
h_{F W}=\frac{k_{l}}{D_{h}}\left[\left(0.048 R e_{l}^{0.69} \operatorname{Pr}_{l}^{0.34} \frac{\Phi_{v}}{X_{t t}}\right)^{2}+\left(3.2 \times 10^{-7} R e_{l}^{-0.38} S u_{v o}^{1.39}\right)^{2}\right]^{0.5}
\end{gathered}
$$

where $R e_{l}$ is liquid Reynolds number, $G_{s t}$ is steam only mass flux, and $P r_{l}$ is liquid Prandtl number.

\subsection{Dropwise condensation modeling overview}

In dropwise condensation, droplet departure sizes and sweeping periods are influenced by flow conditions (i.e. steam mass flux and steam quality) and affect the thermal resistance of liquid, thereby regulating dropwise condensation heat transfer. In horizontal channels, vapor-droplet interfacial shear stresses induce droplet departure, whereas gravity dominates droplet departure in quiescent flows. Average flow condensation heat fluxes were obtained by integrating heat transfer through all the droplets on the surface of a unit area,

$$
\begin{gathered}
q^{\prime \prime}{ }_{D W}=\int_{d_{\min }}^{d_{\max }} \dot{Q}_{d r o p}(d) A(d) d(d) \\
h_{D W}=\frac{q^{\prime \prime}{ }_{D W}}{T_{f}-T_{S}}
\end{gathered}
$$

where $\dot{Q}_{d r o p}(d)$ is the heat transfer rate through the base (droplet-solid contact area) of one droplet with a diameter $d, A(d) d(d)$ is the differential area fraction occupied by droplets with diameter of $d$ to $d+d(d), d_{\max }$ and $d_{\min }$ are respectively the largest and the smallest droplet diameters on the condensation surface, $T_{v}$ is the vapor saturation temperature, and $T_{s}$ is condensation surface 
temperature. The droplet departure diameter is premised to be the largest droplet diameter on the surface.

\subsection{Heat transfer through a single droplet}

Across a single droplet, the thermal resistances are between the vapor $\left(T_{v}\right)$ and surface temperatures $\left(T_{s}\right)$, the interfacial thermal resistance due to the droplet curvature $\left(R_{l v}\right)$, conduction thermal resistance in the droplet $\left(R_{d r o p}\right)$, and conduction thermal resistance of the a surface promoter coating $\left(R_{\text {coat }}\right)$, as shown in Fig. 2. Since these resistances are in series, the general equation for heat flux through a droplet of diameter $\mathrm{d}$ is

$$
\dot{Q}_{d r o p}(d)=\frac{T_{v}-T_{s}}{R_{l v}+R_{d r o p}+R_{c o a t}}
$$

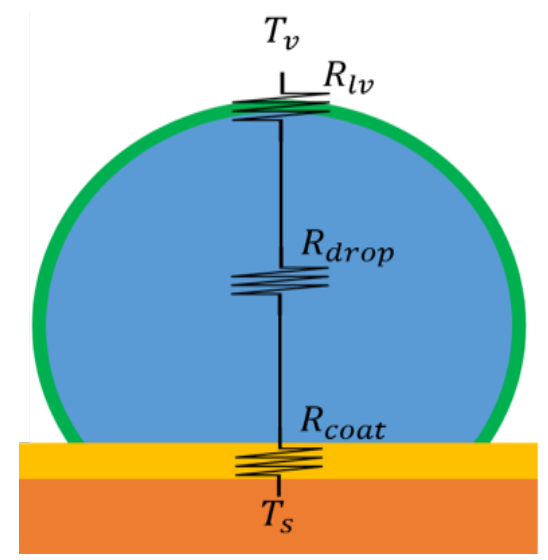

Fig. 2 Resistor analogy for condensation heat transfer through a droplet

Table 1 and Fig. 3 compare models developed by Le Fevre and Rose [46], Bonner [56], and Kim and Kim [12] for heat fluxes through droplets of different diameters at the same thermal conditions. Results from the Le Fevre and Rose model [46] are significantly larger than the other two, perhaps because the thermal resistance in promoter layer and effects of contact angle were not included. The Bonner model [56], adopted in this research, modified Le Fevre and Rose's model [46] by adding the 
effects of contact angle and the thermal resistance in the surface promoter. Leach et al. [57] experimentally and numerically investigated growth rates of droplets with different sizes. Small droplets (e.g., $d<50 \mu \mathrm{m}$ ) provided 15 times higher heat fluxes than the larger droplets, and, therefore, they contributed equivalent condensation rates even though these small droplets only occupied 5\% of the condensation surface.

Table 1 Thermal resistance in the models by Le Fevre and Rose [46], Bonner [56] and Kim and Kim [12]

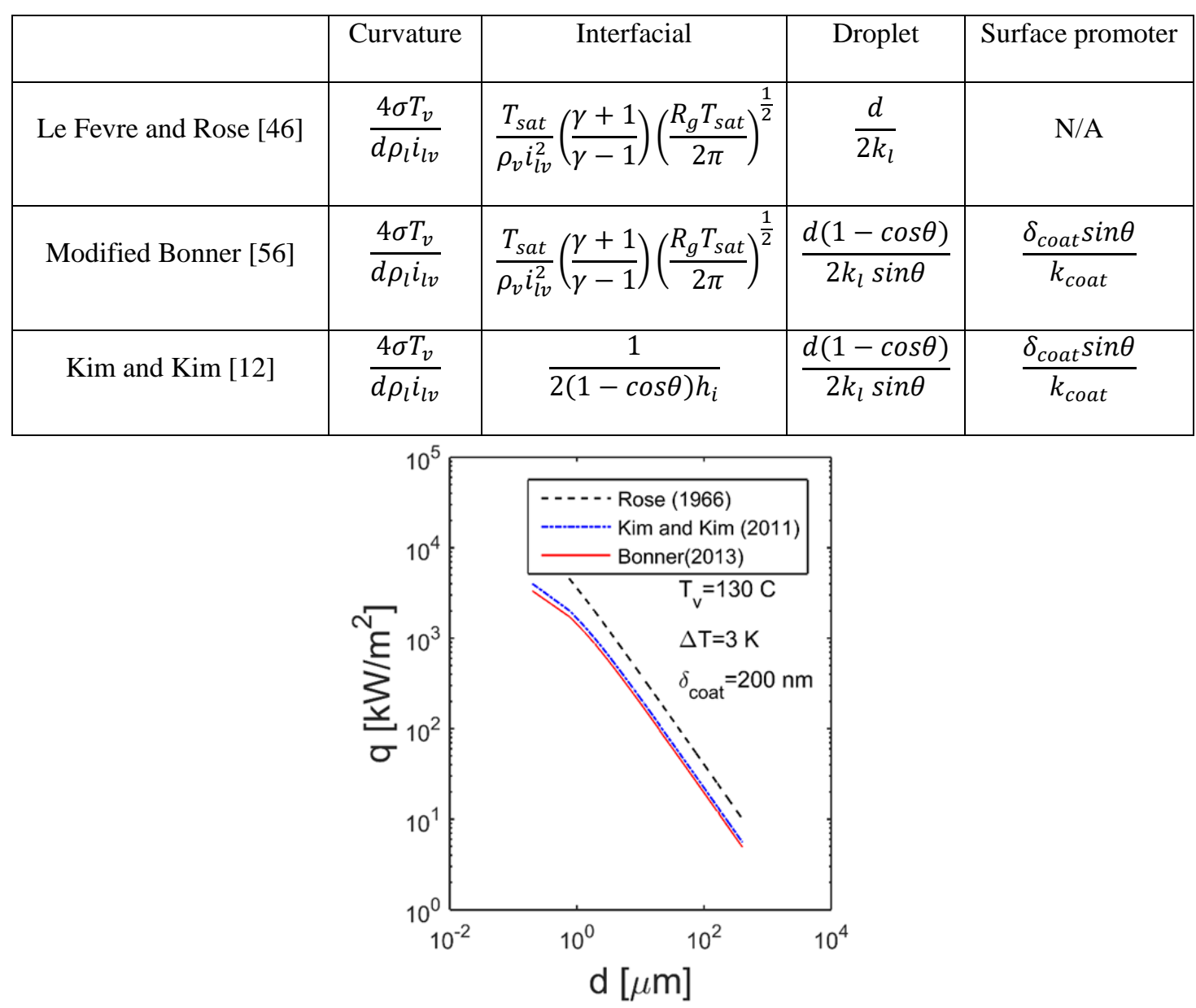

Fig. 3 Heat flux through droplet bases using three models developed by Rose [46], Kim and Kim [12] and Bonner [56] at saturation temperature of $130^{\circ} \mathrm{C}$, subcooling of $3^{\circ} \mathrm{C}$ and surface promoter thickness of $200 \mathrm{~nm}$ 
Leach et al. [57] studied the growth rate of condensing droplets at different sizes and found that droplets with diameters smaller than $50 \mu \mathrm{m}$ have the same growth rate (i.e., volumetric growth rate per unit base area). This observation was added to the Bonner model [56] as the heat transfer rate formula in this research,

$$
\begin{gathered}
\dot{Q}_{d r o p}(d)=\frac{\left(T_{v}-T_{s}-\frac{4 \sigma T_{v}}{d \rho_{l} i_{l v}}\right)\left(\frac{\pi d^{2}}{4}\right)\left(\cos ^{2} \theta\right)}{\frac{T_{s a t}}{\rho_{v} i_{l v}^{2}}\left(\frac{\gamma+1}{\gamma-1}\right)\left(\frac{R_{g} T_{s a t}}{2 \pi}\right)^{\frac{1}{2}}+\frac{d(1-\cos \theta)}{2 k_{l} \sin \theta}+\frac{\delta_{\text {coat }} \sin \theta}{k_{\text {coat }}}} \text { when } d>50 \mu m \\
\dot{Q}_{d r o p}(d)=\frac{\left(T_{v}-T_{s}-\frac{4 \sigma T_{v}}{D \rho_{l} i_{l v}}\right)\left(\frac{\pi d_{c o}^{2}}{4}\right)\left(\cos ^{2} \theta\right)}{\frac{T_{s a t}}{\rho_{v} i_{l v}^{2}}\left(\frac{\gamma+1}{\gamma-1}\right)\left(\frac{R_{g} T_{s a t}}{2 \pi}\right)^{\frac{1}{2}}+\frac{d(1-\cos \theta)}{2 k_{l} \sin \theta}+\frac{\delta_{\text {coat }} \sin \theta}{k_{\text {coat }}}} \text { when } d \leq 50 \mu m
\end{gathered}
$$

where $\sigma$ is the water surface tension, $\theta$ is equilibrium contact angle, $i_{l}$ is the latent heat of evaporation of water, $\gamma$ is specific heat ratio of saturated water, $d_{c o}$ is the cutoff diameter (i.e. $50 \mu \mathrm{m}$ ), and $\delta_{\text {coat }}$ is the Teflon ${ }^{\mathrm{TM}}$ coating thickness. The numerator in equation (10) remains constant, while the droplet size affects the droplet term in the denominator.

\subsection{Droplet size distribution}

Because liquid thermal resistance is proportional to droplet size, heat fluxes and thus condensing heat transfer coefficients depend on the droplet size distribution. Equations (11) and (12) calculate the size distribution of large and small droplets using the cutoff size ( $\left.d_{e}\right)$ proposed by Wu and Maa [50]; droplets with diameter smaller than $d_{e}$ (i.e., the distance between closest nucleation sites) grow mainly through direct condensation, while droplet larger than $d_{e}$ grow through coalescence,

$$
\begin{gathered}
a_{l}(d)=n \frac{2}{d_{\max }}\left(\frac{d}{d_{\max }}\right)^{-\frac{2}{3}} \text { for } d>d_{e} \\
a_{S}(d)=\frac{2}{3 d_{e}^{3} d_{\max }}\left(\frac{d_{e}}{d_{\max }}\right)^{-\frac{2}{3}} \frac{\left(\frac{d}{2}\right)^{3}\left(d_{e}-d_{\min }\right)}{d-d_{\min }} \frac{\frac{A_{1} d}{2}+A_{2}}{\frac{A_{1} d_{e}}{2}+A_{2}} \exp \left(B_{1}+B_{2}\right) \text { for } d<d_{e}
\end{gathered}
$$




$$
\begin{gathered}
A_{1}=\frac{\theta(1-\cos \theta)}{4 k_{\text {coat }} \sin \theta} \\
A_{2}=\frac{1}{2 h_{i}}+\frac{\delta_{\text {coat }}(1-\cos \theta)}{k_{\text {coat }} \sin ^{2} \theta} \\
B_{1}=\frac{A_{2}}{\tau A_{1}}\left[\frac{d_{e}^{2}-d^{2}}{8}+\frac{d_{\text {min }}}{4}\left(d_{e}-d\right)-\frac{d_{\text {min }}^{2}}{4} \ln \left(\frac{d-d_{\text {min }}}{d_{e}-d_{\text {min }}}\right)\right] \\
B_{2}=\frac{A_{3}}{2 \tau A_{1}}\left[d_{e}-d-d_{\text {min }} \ln \left(\frac{d-d_{\text {min }}}{d_{e}-d_{\text {min }}}\right)\right] \\
\tau=\frac{3 d_{e}^{2}\left(\frac{A_{2} d_{e}}{2}+A_{3}\right)^{2}}{A_{1}\left(11 A_{2} d_{e}^{2}-14 A_{2} d_{e} d_{\text {min }}+8 A_{3} d_{e}-11 A_{3} d_{\text {min }}\right)}
\end{gathered}
$$

where $a_{s}(d)$ and $a_{l}(d)$ are the size distributions of droplets smaller and larger than $d_{e}$, respectively, $\tau$ is the sweeping period obtained by setting continuity of $a_{l}(d)$ and $a_{s}(d)$ at $d=d_{e}$. The cutoff size is defined as

$$
d_{e}=\frac{0.385}{d_{\min }}
$$

where $d_{\min }$ is the nucleation size derived by Graham and Griffith [48] using heterogeneous droplet nucleation theory,

$$
d_{\min }=\frac{T_{s a t} \sigma_{l v}}{\rho_{l} i_{l v} \Delta T}
$$

Therefore, the dropwise condensation heat flux is the summation of the heat transfer rate through all droplets on a unit area,

$$
q_{D W}^{\prime \prime}=\int_{d_{\min }}^{d_{e}} \dot{Q}(d) a_{s}(d) d(d)+\int_{d_{e}}^{d_{\max }} \dot{Q}(d) a_{l}(d) d(d) .
$$

The dropwise condensation heat transfer coefficient the ratio of heat flux to subcooling degree of the surface,

$$
h_{D W}=\frac{q^{\prime \prime} D W}{\Delta T} .
$$


Fig. 4 depicts dropwise condensation heat transfer coefficients with respect to the droplet departure sizes at saturation temperature of $130^{\circ} \mathrm{C}$, subcooling degree of $3^{\circ} \mathrm{C}$, and Teflon ${ }^{\mathrm{TM}}$ coating thickness of $200 \mathrm{~nm}$, corresponding to experimental conditions [52]. The equilibrium contact angle on the coated surface was measured to be $110^{\circ}$ using goniometer.

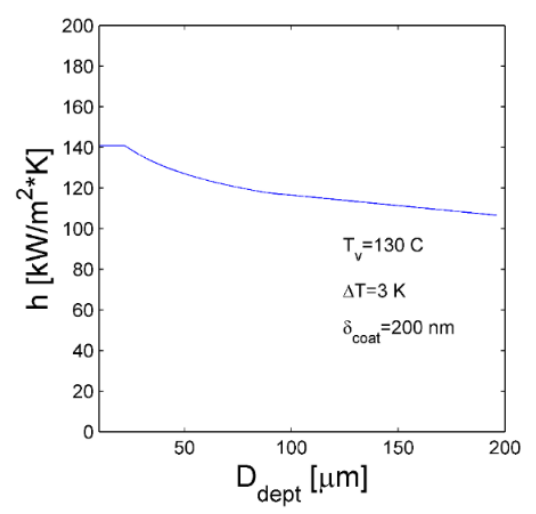

Fig. 4 Heat transfer coefficients with respect to droplet departure size

\subsection{Droplet departure size}

Dropwise condensation heat transfer coefficients strongly depend on the droplet departure size (Fig.

5) which is the largest droplet on the surface and therefore affects liquid thermal resistance and droplet populations [e.g., $d_{\max }$ in Equations (12) and (13)]. Antonini et al. [58] modified the Brown et al. correlation [59] of contact angle and adherence, and developed equation (17) for adhering forces. The drag force obtained from equation (19) increases with increasing droplet size at higher order than the adherence. In this research, droplet departure is premised to happen when the drag force exerted on the droplets by flowing vapor exceeds the adherence between the droplet and the surface.
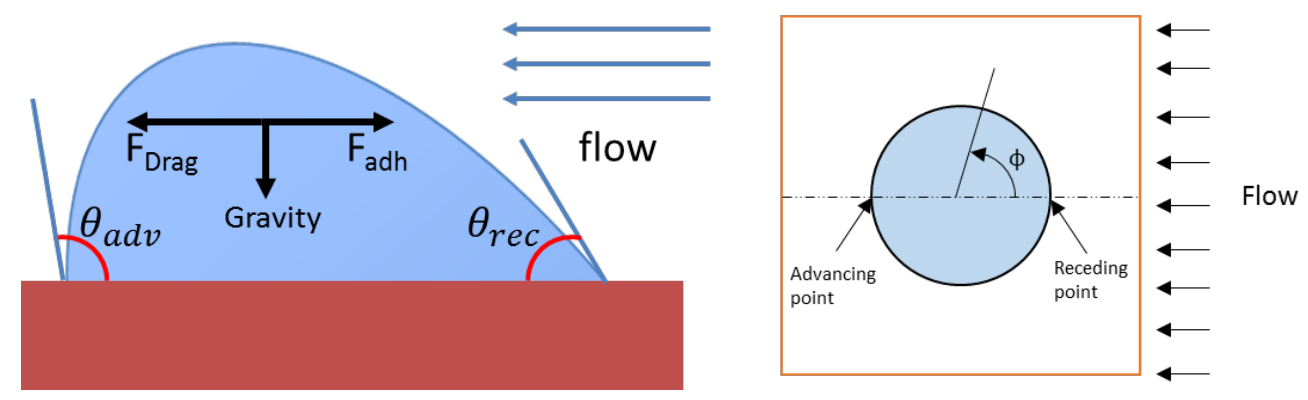
Fig. 5 Force balance on a droplet under shearing flow (left) and the top view of the droplet Adhesion forces are developed through contact angle hysteresis. Researchers [58, 60-63] investigated contact angle hysteresis and the resultant adhesion forces between droplets and surfaces. In this research, equation (17) is utilized for the adhesion force,

$$
F_{a d h}=-\gamma \int_{0}^{2 \pi} \cos \theta \cos \phi r d \phi
$$

where $\theta$ is the dynamic contact angle varying along the contact line, $\phi$ is the azimuthal angle in the top view in Fig. 5 (right). The dynamic contact angle is modelled using a third-order polynomial proposed by ElSherbini and Jacobi [64],

$$
\cos (\theta)=2 \frac{\cos \theta_{a d v}-\cos \theta_{r e c}}{\pi^{3}} \phi^{3}-3 \frac{\cos \theta_{a d v}-\cos \theta_{r e c}}{\pi^{2}} \phi^{2}+\cos \theta_{a d v} \phi
$$

At different flow conditions (i.e. steam mass fluxes and steam qualities), the relatively velocities of vapor over droplets vary. Shear forces are estimated using the drag force equation:

$$
\begin{gathered}
F_{d}=\frac{1}{2} C_{d} \rho_{v} A_{p} U_{v}^{2} \\
U_{v}=\frac{G x}{\rho_{v} \alpha}
\end{gathered}
$$

where $F_{d}$ is the drag force, $C_{d}$ is the drag coefficient, $U_{v}$ is the vapor velocity, $A_{p}$ is the projected area, $G$ is the steam velocity, and $\alpha$ is the void fraction.

CFD simulations were conducted using FLUENT ${ }^{\mathrm{TM}}$ to evaluate the drag forces applied to solid spherical caps of same projected area as deformed ones observed in experiments. These simulations investigated droplet diameters of 25-100 $\mu \mathrm{m}$ and vapor velocities of 5-25 m/s, which are equivalent to flow conditions for steam mass fluxes of $35-100 \mathrm{~kg} / \mathrm{m}^{2} \mathrm{~s}$ and qualities of $0.2-0.8$. Geometry modelling was completed in ANSYS design modeler, where the channel was divided into multiple zones for multi scale meshing (Fig. 6 and Fig. 7). For boundary layer calculations, thirty and ten 
inflation layers were created for the bottom and top surfaces, respectively. For grid independence, 3-4 cases were run at different meshing sizes for each scenario and consistent results were observed. Ultimately, there were 1-3 million elements in the mesh depending on droplet size.

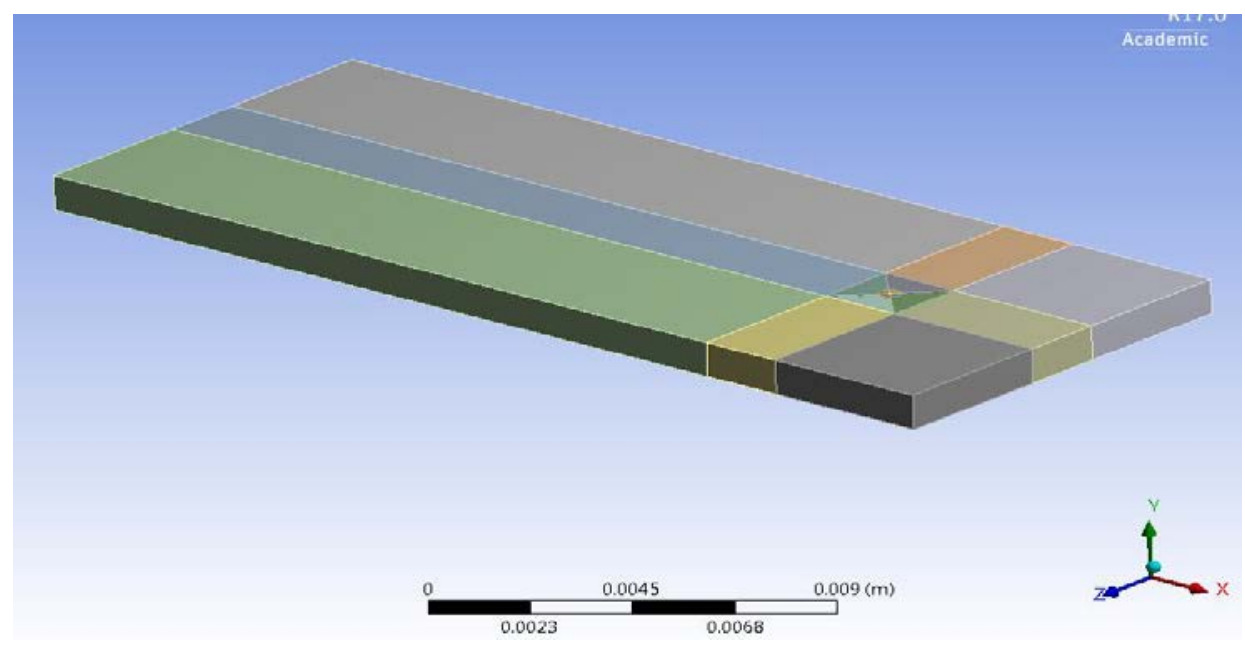

Fig. 6 Multi-zone model for droplet in mini-gap in FLUENT
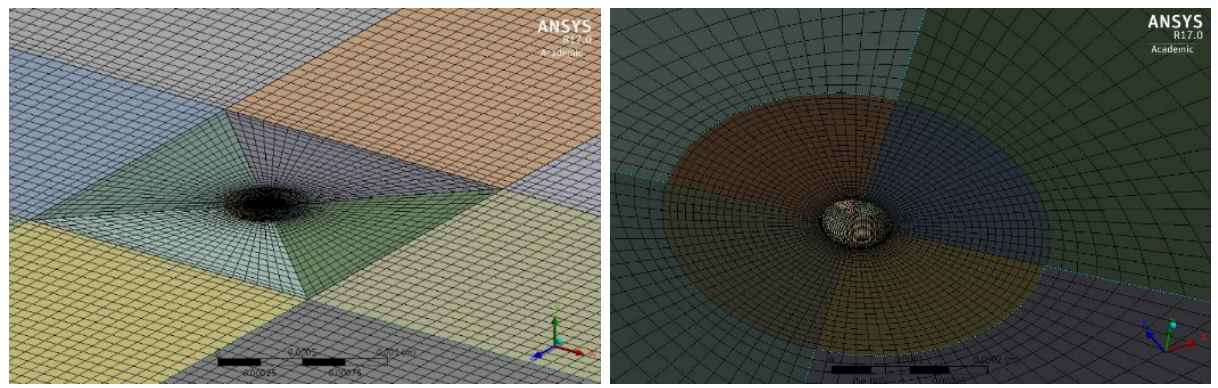

Fig. 7 Multi-scale meshing in FLUENT for determining drag force on droplet

The $\kappa-\omega$ SST model low-Re correction was employed for the simulation due to its ability to solve for the confined flow and near-wall field. Drag force simulations were run for droplet diameters of 25, 50 and $100 \mu \mathrm{m}$, at flow velocities of 5, 10, 15, 20, 25 and $30 \mathrm{~m} / \mathrm{s}$. FLUENT calculated the drag force exerted on the droplet surfaces and drag coefficients $\left(C_{d}\right)$. The average values of drag coefficients at six velocities were all approximately 0.45 with average percentage variances of $8.7 \%, 7.4 \%$ and $5.1 \%$ for droplet diameters of 25, 50 and $100 \mu \mathrm{m}$, respectively (Fig. 8). 

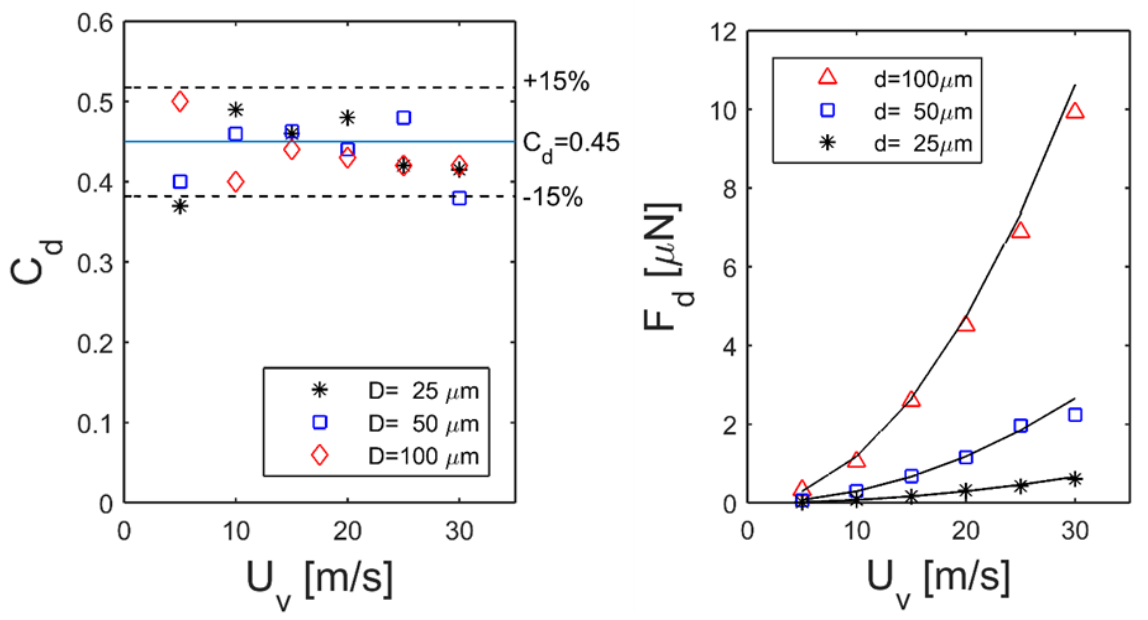

Fig. 8 Drag coefficients of vapor flow on droplet at various velocity and droplet sizes

Sommers et al. [65] studied critical velocities of shearing flow to sweep droplets from vertical surfaces and determined the drag coefficient. Milne and Amirfazli [61] evaluated drag coefficients by investigating incipient motion of droplet on hydrophilic, hydrophobic and superhydrophobic surfaces under shearing air flow in a wind tunnel. Both studies saw a consistent drag coefficient between 0.44 and 0.45. Volynskii [66], Lane [67], and Morsi [68] observed similar drag coefficients (i.e., 0.44-0.45) of deformable droplets and rigid spheres. Combined with the FLUENT simulations, a constant drag coefficient of 0.45 is assumed for this model. Fig. 8 (left) compares the drag forces from simulations and using a constant drag coefficient of 0.45. Fig. 9 depicts predicted droplet departure sizes at steam mass fluxes of $35-200 \mathrm{~kg} / \mathrm{m}^{2} \mathrm{~s}$ and steam qualities of $0.2-0.9$. Increasing steam mass fluxes and steam qualities increase vapor velocity and in turn decrease droplet departure size. 


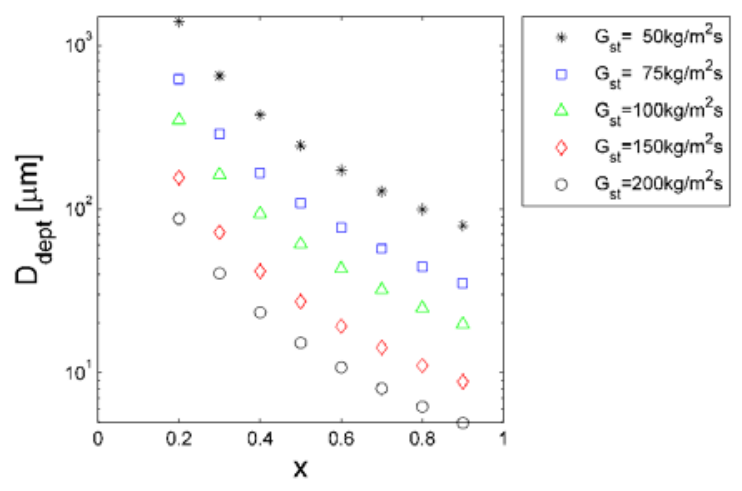

Fig. 9 Droplet departure diameter at different steam mass fluxes and qualites

In order to validate the model, experiments were conducted in an open-loop apparatus using campus steam; the apparatus description was reported by Chen and Derby [52]. Simultaneous droplet dynamics and heat transfer measurements were observed in two copper mini-channels, with hydraulic diameters of $0.95 \mathrm{~mm}$ (i.e., cross sectional area: $10 \mathrm{~mm}$ by $0.5 \mathrm{~mm}$ ) and $1.8 \mathrm{~mm}$ (i.e., cross sectional area: $10 \mathrm{~mm}$ by $1.0 \mathrm{~mm}$ ). Experimentally-obtained droplet departure sizes were compared with the predicted results from the model at steam mass fluxes of 50 and $75 \mathrm{~kg} / \mathrm{m}^{2} \mathrm{~s}$ and steam qualities of 0.45 and 0.65 (Fig. 10). The axial and lateral lengths of departing droplets were measured using Photron FASTCAM Viewer software. The averages of axial and lateral departure sizes in the experimetal were taken as the nominal departure sizes and compared with the results from the model in Table 2. To ensure shear-induced departure, size measurements were performed on droplets completing the series of nucleation, growth, coalescence and departure. The nominal departure sizes are the average of lengths in axial and lateral directions. The predicted departure size is on average $6.5 \%$ smaller than the mean value of the two principal sizes. The uncertainty of the measurements was \pm 4 pixel (i.e., equivalent to $\pm 11.2 \mu \mathrm{m}$ ) with the magnification of 5.0 in the lens and camera pixel size of $14 \mu \mathrm{m}$. 

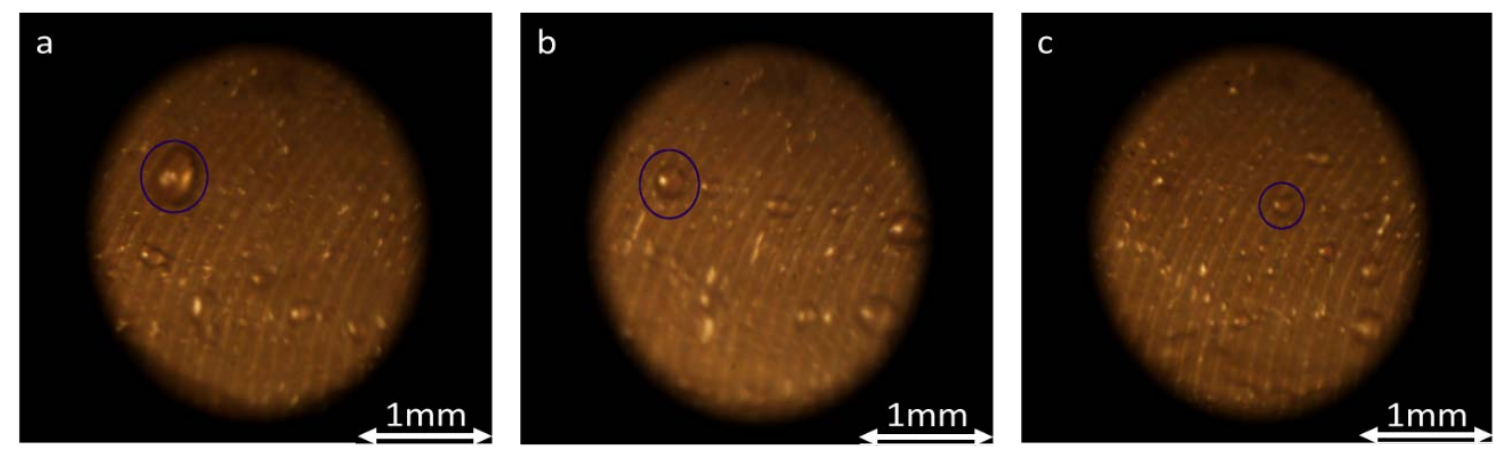

Fig. 10 Droplet departure sizes observed in experiments at a) $\left.G=50 \mathrm{~kg} / \mathrm{m}^{2} \mathrm{~s}, x=0.45, \mathrm{~b}\right) \mathrm{G}=50$ $\mathrm{kg} / \mathrm{m}^{2} \mathrm{~s}, x=0.65$, and c) $G=75 \mathrm{~kg} / \mathrm{m}^{2} \mathrm{~s}, x=0.5$

Table 2 Experimental and predicted droplet departure sizes

\begin{tabular}{|c|c|c|c|}
\hline Steam mass flux & Quality & Experimental results & Predicted results \\
\hline 50 & 0.45 & $370 \pm 11.2 \mu \mathrm{m}$ & 364 \\
\hline 50 & 0.65 & $231 \pm 11.2 \mu \mathrm{m}$ & 225 \\
\hline 75 & 0.5 & $131 \pm 11.2 \mu \mathrm{m}$ & 111 \\
\hline
\end{tabular}

\section{Comparison with experimental data}

Measured flow condensation heat transfer coefficients in the 0.95-mm mini-gap are shown in Fig. 11. It should be noted that this model is not designed for steam qualities lower than 0.2 , because the void fraction changes dramatically at these low qualities. Increasing steam mass flux and steam quality increases heat transfer coefficients through increasing interfacial shear, thereby decreasing droplet departure size and subsequently lowering the thermal resistance. At increasing steam mass fluxes, dropwise condensation heat transfer coefficients become less dependent on steam quality because most droplets are within the diameter range of $50 \mu \mathrm{m}$ where heat transfer coefficients are independent of droplet sizes. 


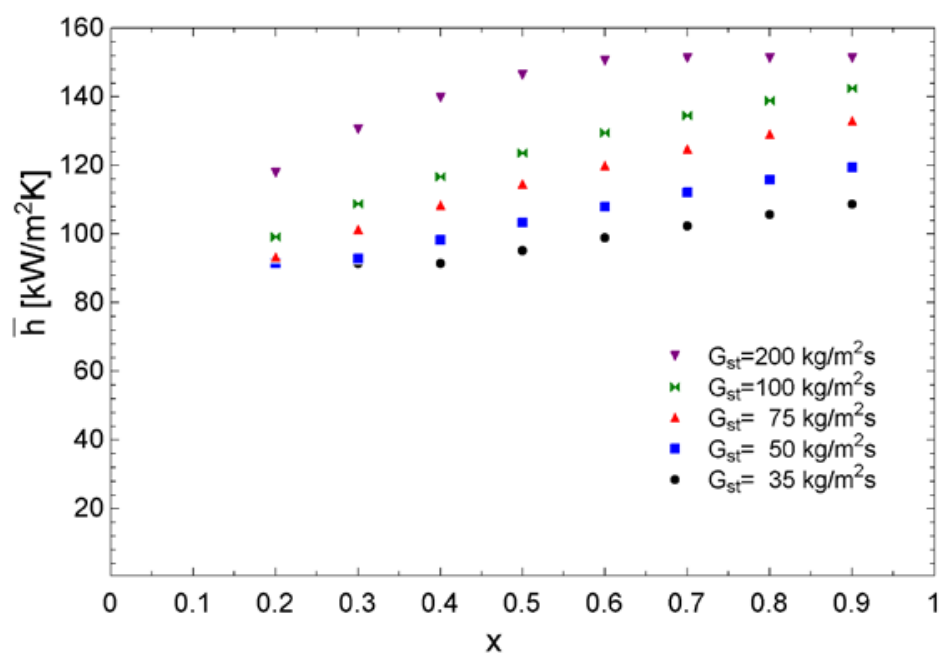

Fig. 11 Droplet departure size at various steam mass fluxes and steam qualites

Predicted and experimental heat transfer coefficients are presented in Fig. 12. All the predictions are all within $-30 \%$ to $+30 \%$ range of relative errors (RE), and most of the data are within $\pm 15 \%$. With no curve fitting in the model, the mean absolute errors (MAE), for the 0.952 and 1.8-mm mini-gaps are $9.6 \%$ and $8.8 \%$, respectively.

$$
M A E=\frac{\sum_{i=1}^{n}\left|\frac{h_{\text {corr }}-h_{\text {exp }}}{h_{\text {exp }}}\right|}{n} \times 100 \%
$$

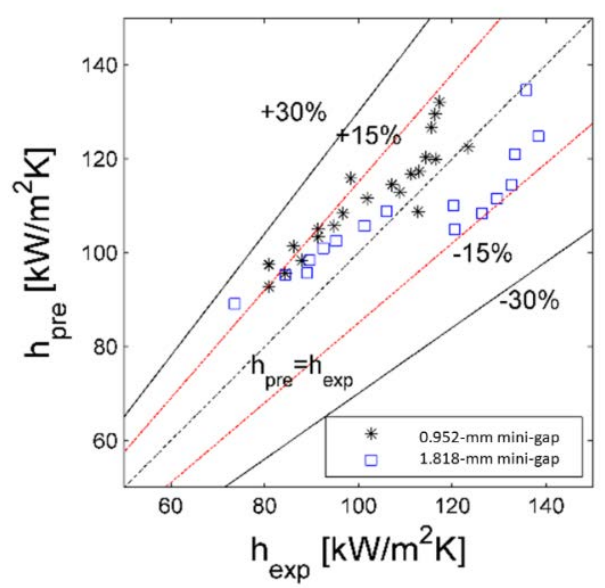

Fig. 12 Droplet departure size at various steam mass fluxes and steam qualities 


\section{CONCLUSIONS}

The following conclusions can be drawn from this study:

- Heat transfer coefficients on hydrophobic surfaces were modeled by weighting filmwise and dropwise condensation areas using void fraction. The filmwise condensation heat transfer coefficients were predicted using the Kim and Mudawar [54] filmwise condensation.

- Heat transfer through single droplets was analyzed using the resistor analogy and droplet size distributions were developed using power law function and population theory to estimate dropwise condensation heat transfer coefficients.

- Heat transfer coefficients significantly depended on the droplet departure size which were predicted using a force balance between drag and adhesion forces. The drag forces were calculated using FLUENT simulations and the adhesion forces were predicted using the Antonini et al. [58] model assisted by the ElSherbini and Jacobi [64] correlation for droplet dynamic contact angles.

- The correlation presented good agreement with the experimental results with relative errors (RE) all within the range of $\pm 30 \%$, and most of the data are within $\pm 15 \%$. With no curve fitting in the model, the mean absolute errors (MAE) for the 0.5-mm and 1-mm deep minigaps are $9.6 \%$ and $8.8 \%$, respectively.

\section{ACKNOWLEDGMENTS}

The authors gratefully acknowledge the partial support of the Electric Power Affiliates Program of Kansas.

\section{NOMENCLATURE}
A
Area
a Droplet size distribution
D Channel diameter 


\begin{tabular}{ll} 
d & Droplet diameter \\
$\mathrm{f}$ & Flow \\
$\mathrm{G}$ & Flow mass flux \\
$\mathrm{i}$ & average heat transfer coefficient \\
$\mathrm{k}$ & Evaporative enthalpy \\
$\mathrm{Pr}$ & Thermal conductivity \\
$\mathrm{Q}$ & Prandtl number \\
$\mathrm{q}$, & Heat transfer rate \\
$\mathrm{R}$ & Heat flux \\
$\mathrm{Re}$ & Thermal resistance \\
$\mathrm{Rg}$ & Reynolds number \\
$\mathrm{Su}$ & Steam vapor gas constant \\
$\mathrm{T}$ & Suratman number \\
$\mathrm{x}$ & Temperature \\
& Quality \\
\hline
\end{tabular}

Greek:

$\alpha \quad$ Void fraction

$\gamma \quad$ Specific heat ratio

$\delta \quad$ Thickness

$\theta \quad$ Contact angle

$\mu \quad$ Dynamics viscosity

$\rho \quad$ Density

$\sigma \quad$ Surface tension

$\tau \quad$ Sweeping period

$\Phi \quad$ Two-phase flow multiplier 
$\mathrm{X}_{\mathrm{tt}} \quad$ Turbulent-turbulent Martinelli parameter

Subscripts:

CondCondensation

co Cutoff droplet diameter (i.e., $50 \mu \mathrm{m}$ )

DW Dropwise condensation

FW Filmwise condensation

$1 \quad$ Liquid

s Surface

sat Saturation

st Steam

t Total condensation areas

V Vapor

vo Vapor only flow

\section{REFERENCES}

[1] J.G. Bustamante, A.S. Rattner, S. Garimella, Achieving near-water-cooled power plant performance with air-cooled condensers, Applied Thermal Engineering, 105 (2016) 362-371.

[2] J.M. Beér, High efficiency electric power generation: The environmental role, Progress in Energy and Combustion Science, 33(2) (2007) 107-134.

[3] H.B. Bacha, M. Bouzguenda, M. Abid, A. Maalej, Modelling and simulation of a water desalination station with solar multiple condensation evaporation cycle technique, Renewable energy, 18(3) (1999) 349-365.

[4] F. Zhang, X. Yang, C. Wang, Liquid water removal from a polymer electrolyte fuel cell, Journal of the Electrochemical Society, 153(2) (2006) A225-A232. 
[5] L. Liu, A.M. Jacobi, The effects of hydrophilicity on water drainage and condensate retention on air-conditioning evaporators, (2006).

[6] A. Lee, M.-W. Moon, H. Lim, W.-D. Kim, H.-Y. Kim, Water harvest via dewing, Langmuir, 28(27) (2012) 10183-10191.

[7] T.B. Peters, M. McCarthy, J. Allison, F.A. Dominguez-Espinosa, D. Jenicek, H.A. Kariya, W.L. Staats, J.G. Brisson, J.H. Lang, E.N. Wang, Design of an Integrated Loop Heat Pipe Air-Cooled Heat Exchanger for High Performance Electronics, IEEE Transactions on Components, Packaging and Manufacturing Technology, 2(10) (2012) 1637-1648.

[8] M.M. Derby, A. Chatterjee, Y. Peles, M.K. Jensen, Flow condensation heat transfer enhancement in a mini-channel with hydrophobic and hydrophilic patterns, International Journal of Heat and Mass Transfer, 68 (2014) 151-160.

[9] E. Schmidt, W. Schurig, W. Sellschopp, Versuche über die Kondensation von Wasserdampf in Film-und Tropfenform, Technische Mechanik und Thermodynamik, 1(2) (1930) 53-63.

[10] T.Q. Liu, W. Sun, C.F. Mu, S.B. Xia, X.Y. Sun, A mechanism study of initial droplet formation for dropwise condensation, Heat Transfer - Asian Research, 42(2) (2013) 151-162.

[11] M. Abu-Orabi, Modeling of heat transfer in dropwise condensation, International journal of heat and mass transfer, 41(1) (1998) 81-87.

[12] S. Kim, K.J. Kim, Dropwise condensation modeling suitable for superhydrophobic surfaces, Journal of heat transfer, 133(8) (2011) 081502.

[13] S. Lee, K. Cheng, V. Palmre, M.M.H. Bhuiya, K.J. Kim, B.J. Zhang, H. Yoon, Heat transfer measurement during dropwise condensation using micro/nano-scale porous surface, International Journal of Heat and Mass Transfer, 65 (2013) 619-626.

[14] B. Peng, X. Ma, Z. Lan, W. Xu, R. Wen, Analysis of condensation heat transfer enhancement with dropwise-filmwise hybrid surface: Droplet sizes effect, International Journal of Heat and Mass Transfer, 77 (2014) 785-794. 
[15] I. Tanasawa, Y. Funawatashi, J. Ochiai, Experimental study on dropwise condensation-effect of maximum drop size upon the heat transfer coefficient, in: Sixth International Heat Transfer Conference, 7-11 Aug. 1978, Hemisphere Publishing Corp., Washington, DC, USA, 1978, pp. 477482.

[16] R. Wen, Z. Lan, B. Peng, W. Xu, X. Ma, Y. Cheng, Droplet Departure Characteristics and Dropwise Condensation Heat Transfer at Low Steam Pressure, Journal of Heat Transfer, 138(7) (2016) 071501.

[17] P.S. Mahapatra, A. Ghosh, R. Ganguly, C.M. Megaridis, Key design and operating parameters for enhancing dropwise condensation through wettability patterning, International Journal of Heat and Mass Transfer, 92 (2016) 877-883.

[18] B. Peng, X. Ma, Z. Lan, W. Xu, R. Wen, Experimental investigation on steam condensation heat transfer enhancement with vertically patterned hydrophobic-hydrophilic hybrid surfaces, International Journal of Heat and Mass Transfer, 83 (2015) 27-38.

[19] M. Derby, H.J. Lee, Y. Peles, M.K. Jensen, Condensation heat transfer in square, triangular, and semi-circular mini-channels, International Journal of Heat and Mass Transfer, 55(1) (2012) 187-197. [20] D. Tanner, C. Potter, D. Pope, D. West, Heat transfer in dropwise condensation—Part I The effects of heat flux, steam velocity and non-condensable gas concentration, International Journal of Heat and Mass Transfer, 8(3) (1965) 419IN5421-420426.

[21] S. Hatamiya, H. Tanaka, Study on the mechanism of dropwise condensation(1st report, measurement of heat transfer coefficient of steam at low pressure), Transactions of the Japan Society of Mechanical Engineers, 52(476) (1986) 1828-1834.

[22] A. Neumann, A. Abdelmessih, A. Hameed, The role of contact angles and contact angle hysteresis in dropwise condensation heat transfer, International Journal of Heat and Mass Transfer, 21(7) (1978) 947-953. 
[23] X. Ma, X.-F. Chen, T. Bai, J.-B. Chen, A new mechanism for condensation heat transfer enhancement: effect of the surface free energy difference of condensate and solid surface, Journal of Enhanced Heat Transfer, 11(4) (2004).

[24] K. Holden, A. Wanniarachchi, P. Marto, D. Boone, J. Rose, The use of organic coatings to promote dropwise condensation of steam, Journal of heat transfer, 109(3) (1987) 768-774.

[25] T. Haraguchi, R. Shimada, S. Kumagai, T. Takeyama, The effect of polyvinylidene chloride coating thickness on promotion of dropwise steam condensation, International journal of heat and mass transfer, 34(12) (1991) 3047-3054.

[26] G. Koch, D. Zhang, A. Leipertz, Condensation of steam on the surface of hard coated copper discs, Heat and mass transfer, 32(3) (1997) 149-156.

[27] X. Ma, J. Chen, D. Xu, J. Lin, C. Ren, Z. Long, Influence of processing conditions of polymer film on dropwise condensation heat transfer, International Journal of Heat and Mass Transfer, 45(16) (2002) 3405-3411.

[28] X. Ma, B. Wang, D. Xu, J. Lin, Lifetime test of dropwise condensation on polymer - coated surfaces, Heat Transfer—Asian Research, 28(7) (1999) 551-558.

[29] X. Ma, B. Tao, J. Chen, D. Xu, J. Lin, Dropwise condensation heat transfer of steam on a polytethefluoroethylene film, Journal of Thermal Science, 10(3) (2001) 247.

[30] B.J. Zhang, C. Kuok, K.J. Kim, T. Hwang, H. Yoon, Dropwise steam condensation on various hydrophobic surfaces: Polyphenylene sulfide (PPS), polytetrafluoroethylene (PTFE), and selfassembled micro/nano silver (SAMS), International Journal of Heat and Mass Transfer, 89 (2015) 353-358.

[31] A. Das, H. Kilty, P. Marto, G. Andeen, A. Kumar, The use of an organic self-assembled monolayer coating to promote dropwise condensation of steam on horizontal tubes, Journal of heat transfer, 122(2) (2000) 278-286. 
[32] S. Vemuri, K. Kim, B. Wood, S. Govindaraju, T. Bell, Long term testing for dropwise condensation using self-assembled monolayer coatings of n-octadecyl mercaptan, Applied thermal engineering, 26(4) (2006) 421-429.

[33] G. Pang, J.D. Dale, D.Y. Kwok, An integrated study of dropwise condensation heat transfer on self-assembled organic surfaces through Fourier transform infra-red spectroscopy and ellipsometry, International Journal of Heat and Mass Transfer, 48(2) (2005) 307-316.

[34] L. Chen, S. Liang, R. Yan, Y. Cheng, X. Huai, S. Chen, n-Octadecanethiol self-assembled monolayer coating with microscopic roughness for dropwise condensation of steam, Journal of Thermal Science, 18(2) (2009) 160-165.

[35] R.W. Bonner, Dropwise condensation life testing of self assembled monolayers, in: 2010 14th International Heat Transfer Conference, American Society of Mechanical Engineers, 2010, pp. 221226.

[36] Q. Yang, A. Gu, Dropwise condensation on SAM and electroless composite coating surfaces, Journal of chemical engineering of Japan, 39(8) (2006) 826-830.

[37] M. Rausch, A. Fröba, A. Leipertz, Dropwise condensation heat transfer on ion implanted aluminum surfaces, International Journal of heat and Mass transfer, 51(5) (2008) 1061-1070.

[38] M. Rausch, A. Leipertz, A. Fröba, Dropwise condensation of steam on ion implanted titanium surfaces, International Journal of Heat and Mass Transfer, 53(1) (2010) 423-430.

[39] Q. Zhao, B. Burnside, Dropwise condensation of steam on ion implanted condenser surfaces, Heat Recovery Systems and CHP, 14(5) (1994) 525-534.

[40] A. Leipertz, K.-H. Choi, Selected adjustment of dropwise condensation on ion implanted surfaces, in, Google Patents, 2002.

[41] L. Cheng, T. Chen, Heat transfer and flow friction characteristics of a compact plate-type condenser, ASME HEAT TRANSFER DIV PUBL HTD, 361 (1998) 489-496. 
[42] Z. Lan, X. Ma, S. Wang, M. Wang, X. Li, Effects of surface free energy and nanostructures on dropwise condensation, Chemical Engineering Journal, 156(3) (2010) 546-552.

[43] M. Izumi, S. Kumagai, R. Shimada, N. Yamakawa, Heat transfer enhancement of dropwise condensation on a vertical surface with round shaped grooves, Experimental Thermal and Fluid Science, 28(2-3) (2004) 243-248.

[44] Y.-A. Lee, L.-S. Kuo, T.-W. Su, C.-C. Hsu, P.-H. Chen, Orientation effects of nanoparticlemodified surfaces with interlaced wettability on condensation heat transfer, Applied Thermal Engineering, 98 (2016) 1054-1060.

[45] X. Li, P. Cheng, Lattice Boltzmann simulations for transition from dropwise to filmwise condensation on hydrophobic surfaces with hydrophilic spots, International Journal of Heat and Mass Transfer, 110 (2017) 710-722.

[46] E. Le Fevre, J. Rose, A theory of heat transfer by dropwise condensation, in: Chemical Engineering Progress, AMER INST CHEMICAL ENGINEERS 345 E 47TH ST, NEW YORK, NY 10017, 1966, pp. 86-\&.

[47] E. Le Fevre, J. Rose, An experimental study of heat transfer by dropwise condensation, International Journal of Heat and Mass Transfer, 8(8) (1965) 1117-1133.

[48] C. Graham, P. Griffith, Drop size distributions and heat transfer in dropwise condensation, International Journal of Heat and Mass Transfer, 16(2) (1973) 337-346.

[49] H. Tanaka, A theoretical study of dropwise condensation, ASME J. Heat Transfer, 97(1) (1975) 72-78.

[50] W.H. Wu, J.R.M. Maa, On the heat transfer in dropwise condensation, The chemical engineering journal, 12(3) (1976) 225-231.

[51] J.R. Maa, Drop size distribution and heat flux of dropwise condensation, The Chemical Engineering Journal, 16(3) (1978) 171-176. 
[52] X. Chen, M.M. Derby, Combined visualization and heat transfer measurements for steam flow condensation in hydrophilic and hydrophobic mini-gaps, Journal of Heat Transfer, 138(9) (2016) 091503.

[53] D. Butterworth, A comparison of some void-fraction relationships for co-current gas-liquid flow, International Journal of Multiphase Flow, 1(6) (1975) 845-850.

[54] S.-M. Kim, I. Mudawar, Universal approach to predicting heat transfer coefficient for condensing mini/micro-channel flow, International Journal of Heat and Mass Transfer, 56(1) (2013) 238-250.

[55] H. Soliman, On the annular - to - wavy flow pattern transition during condensation inside horizontal tubes, The Canadian Journal of Chemical Engineering, 60(4) (1982) 475-481.

[56] R.W. Bonner, Correlation for dropwise condensation heat transfer: Water, organic fluids, and inclination, International Journal of Heat and Mass Transfer, 61 (2013) 245-253.

[57] R. Leach, F. Stevens, S. Langford, J. Dickinson, Dropwise condensation: experiments and simulations of nucleation and growth of water drops in a cooling system, Langmuir, 22(21) (2006) 8864-8872.

[58] C. Antonini, F. Carmona, E. Pierce, M. Marengo, A. Amirfazli, General methodology for evaluating the adhesion force of drops and bubbles on solid surfaces, Langmuir, 25(11) (2009) 61436154.

[59] R. Brown, F. Orr, L. Scriven, Static drop on an inclined plate: analysis by the finite element method, Journal of Colloid and Interface Science, 73(1) (1980) 76-87.

[60] R. Tadmor, P. Bahadur, A. Leh, H.E. N'guessan, R. Jaini, L. Dang, Measurement of lateral adhesion forces at the interface between a liquid drop and a substrate, Physical review letters, 103(26) (2009) 266101.

[61] A. Milne, A. Amirfazli, Drop shedding by shear flow for hydrophilic to superhydrophobic surfaces, Langmuir, 25(24) (2009) 14155-14164. 
[62] S.R. Annapragada, J.Y. Murthy, S.V. Garimella, Droplet retention on an incline, International Journal of Heat and Mass Transfer, 55(5) (2012) 1457-1465.

[63] D. Pilat, P. Papadopoulos, D. Schaffel, D. Vollmer, R. Berger, H.-J. Butt, Dynamic measurement of the force required to move a liquid drop on a solid surface, Langmuir, 28(49) (2012) 16812-16820. [64] A. ElSherbini, A. Jacobi, Liquid drops on vertical and inclined surfaces: I. An experimental study of drop geometry, Journal of colloid and interface science, 273(2) (2004) 556-565.

[65] A. Sommers, J. Ying, K. Eid, Predicting the onset of condensate droplet departure from a vertical surface due to air flow-Applications to topographically-modified, micro-grooved surfaces, Experimental Thermal and Fluid Science, 40 (2012) 38-49.

[66] M. Volynskii, Study of droplet breakings in a gas flow, DAN SSSR, 18(2) (1949).

[67] W. Lane, Breakup of droplets in an air flow, Industrial and Engng. Chem, 43(6) (1951).

[68] S. Morsi, A. Alexander, An investigation of particle trajectories in two-phase flow systems, Journal of Fluid mechanics, 55(02) (1972) 193-208.

(C) 2018. This manuscript version is made available under the CC-BY-NC-ND 4.0 license http://creativecommons.org/licenses/by-nc-nd/4.0/ 